My work has been amongst giris, and the attempts made thus far in teaching scientific method in girls' schools show that such a method will inevitably lead to the development desired by Prof. Armstrong.

Doubtless one of the drawbacks is the difficulty of giving to each member of a large class the opportunity of individual work. I am not sorry, however, to have sometimes laboured under this difficulty myself, as it has brought about the discovery of how much could still be done on the right lines. When necessary I have replaced individual work by a demonstration class, in which the pupils, three or four at a time, have taken it in turns to work in front of the others, the work consisting in the solution of problems such as those suggested in the British Association's report on chemical teaching. The principal results are these: the children take a growing interest in the work, and those who are doubiful how far girls may desire to work with their hands, instead of always sitting still, may be glad to hear that no greater incentive to invention can be given in a demonstration class than the reward of becoming the experimenter for the time being. There is never any lack of suggestion for the next step in the work, and the rapidity with which such work trains the girls to consider the value or defects of any new proposal for the solution of their problem, is sometimes astonishing. In these classes the teacher plays a very small part-at least, apparently - only from time to time directing the suggestions, and giving permission for new work to be started ; invention, experiment, meaning of results, and criticism are all undertaken by the children, and the final "discovery" is their own triumph.

I have often been asked by teachers about the discipline of such a class, since experimental work goes so slowly that they think it would be impossible to keep those who are not actually at work attentive. I can only say that the class consists of a group of people genuinely interested in a common object, and it behaves in the way such groups generally do. If at times a girl's enthusiasm so far carries her away that she rushes from her seat to the experimenting table, the class, with a laugh, excuses her, sympathises with her feelings, and is not disturbed thereby.

It seems unquestionable that the result of such work should have a wider reaching effect than the mere knowledge of certain facts in nature, though such knowledge is also obtained. Where children, through their own work, have been led to observe and then to think, the result may fairly claim to be truly educative, and one is often at a loss to understand what support can be found for the still largely-existing method of teaching not science but "useful information."

Another objection often made to teaching scientific method instead of facts, that it takes too much time, I have already answered in this journal. I may perhaps be permitted to repeat that experiment shows the result of elementary training, of the kind described, to have a lasting influence on the rapidity and comprehension with which new subjects are grasped later on. Buoks, too, which are never put into the hands of beginners, are used with more than ordinary sense at this later stage. I may say that, even from the examination test (which, however, is not always going to be our standard), the results are very favourable. One thing, however, cannot be done by the teaching of scientific method, and that is to prepare for the London Matriculation examination in chemistry in three months-but then, is that altogether to be regretted?

GRACE HEATH.

North London Collegiate School for Girls, November 5.

\section{Italian Scientific Expedition to Monte Rosa.}

IN the summer of this year, my assistant Dr. L. Scofone and I siayed a month at the Alp of Lavez in the valley of Gressoney, near the foot of the Indren glacier, at an altitude of $2450 \mathrm{~m}$., not far from the place where the brothers Schlagintweit spent some days in $185 \mathrm{I}$ while engaged in their well.known scientific observations on Monte Rosa.

We purposed to examine, both chemically and bacteriologically, the composition of the waters of that region (inclusive of snow and ice); some of the analyses (ammonia, nitrites, nitrates and organic matter) were made directly on the spot, where we had a small laboratory. To be able to carry the waters to Turin, for further analysis, we had only to evaporate them, and seal the residues in little glass bottles by means of a blowpipe. The detection of germs was made by using agar and N J. I 307 , VOL. 5 I] gelatine plates enclosed in the well known Petri's glass-boxes; gelatine, agar, pipettes, and other instruments being duly sterilised first in Turin, and then at Lavez, with a good hot air oven. The development of germs was secured by putting the plates in an incubating oven.

We also collected the water of the Indren torrents issuing from the glacier, and measured the amount of suspended matter in the water, which can give an idea of the process of erosion that takes place in the bed of the ice stream.

The results of the various observations will be published in the scientific papers of Turin as soon as the study of the collected material has been completed. It will perhaps interest your readers to know that while the water of the springs, streams and lakes was constantly free from ammonia, there was found a tolerable quantity of it in the snow collected on the summit of the Punta Guifetti or Signal Kuppe, one of the loftiest peaks in the Monte Rosa range, measuring $4539 \mathrm{~m}$. The ice of the Lys Glacier, dug out from the depths of a huge crevasse, also contained ammonia; nitrites and nitrates being absent in every case. Accordingly we found that the water of the Indren stream, during a very hot day, when the melting of the ice was considerable, contained traces of ammonia.

We also found that the ice and snow collected on the various peaks, passes, and snow-fields of the Monte Rosa range, contained a few germs. The number of the species whose germs can thrive at those heights is certainly not large; the usual forms, living in decayed matter and in the intestines, cannot probably endure the condition of temperature, pressure and light of the place.

Turin, October 28.

Piero Giacosa.

\section{Chinese Beliefs about Caves.}

Mr. Herbert SPencer, in his "Principles of Sociology" (3rd edition, New York, vol. i. p. 207), relates the beliefs in the creation of mankind under the ground or in caverns, current among the Todas in Asia, the Basutos in Africa, and at least one-half of the American tribes. A similar belief I have lately found in a Chinese record. In $\mathrm{Li}$ Shih's Siih Póh-wuh-chi (written in the $13^{\text {th }}$ cent. A.D., Japanese edition, 1683 , tom. ii. p. 3) a quotation from the Ning-kwóh-lun runs as follows:"Primitively there was no Liáu-Kién in Shuh (now Sze Chuen); this tribe emanated from red clay in a cave of Teh-yáng mountain, whence bits of the soil had began to roll out, each roll enlarging them, so that at last thereby was created a couple, who gave birth to many."

In another paragraph $\mathrm{Mr}$. Spencer remarks :- "Stationary descendants of troglodytes think that they return into a subterranean other-world whence they emerged (ibid. p. 213). According to this, I would suggest that the same belief, entertained by some aborigines in China, has revived itself among the Taôists, who used to call their paradise the "Cave-Heaven" (Tung-Tièn)-e.g. Twan Ching-Shih describes the "Cave.Heaven" 10,000 lis in circumference and 2600 lis in height (his "Miscellanies," Japanese edition, 1697, tom. ii. p. I), and $\mathrm{Li}$ Shih enumerates thirty-six caves in the empire, all entitled "Heavens" (ibid. tom. i, p. 8).

I5 Blithfield Street, Kensington, W., November 2.

\section{Spots over Dogs' Eyes.}

I would have written a note on this subject long ago, had I not failed to see similar spots general amongst wild animals allied to the dog. The spots may, however, be more general than I am aware. The spots are by no means always tan; a black dog will sometimes have them white, and a white dog black. I have a white and tan fox-terrier, in which the spots are very eye-like and jet black; in a brown bull-pug of mine, the spots are also black. These spots are so eye-like, that when the dogs are asleep they seem at first sight to be wide awake.

Has not the human eyebrow, highly developed in some crude races, as in Australians and Ainos, a similar meaning? The eyebrow gives many sleeping persons the appearance of being awake.

Dunstable. WORTHINGTON G. SMITH.

\section{Gravitation.}

IN his interesting paper upon the "Mechanical Stretching of Liquids" (Phil. Trans. I892, A, p. 370), Prof. Worthington describes a phenomenon of attraction between bodies immersed 